\title{
Mechanisms of Global Warming Impacts on Regional Tropical Precipitation*
}

\author{
CHIA CHOU \\ Research Center for Environmental Change, Academia Sinica, Taipei, Taiwan \\ J. DAVID NEELIN \\ Department of Atmospheric Sciences, University of California, Los Angeles, Los Angeles, California
}

(Manuscript received 25 July 2003, in final form 28 January 2004)

\begin{abstract}
Mechanisms that determine the tropical precipitation anomalies under global warming are examined in an intermediate atmospheric model coupled with a simple land surface and a mixed layer ocean. To compensate for the warm tropospheric temperature, atmospheric boundary layer (ABL) moisture must increase to maintain positive convective available potential energy (CAPE) in convective regions. In nonconvective regions, ABL moisture is controlled by different balances and does not increase as much, creating a spatial gradient of ABL moisture anomalies. Associated with this spatial pattern of the ABL moisture anomalies are two main mechanisms responsible for the anomalous tropical precipitation. In the "upped-ante mechanism," increases in ABL moisture are opposed by imported dry air wherever inflow from nonconvective regions over margins of convective regions occurs. The ABL moisture is not enough to meet the higher "convective ante" induced by the warmer tropospheric temperature, so precipitation is decreased. In the "anomalous gross moist stability mechanism," gross moist stability is reduced due to increased ABL moisture. As a result, convection is enhanced and precipitation becomes heavier over convective regions. While the upped-ante mechanism induces negative precipitation anomalies over the margins of convective regions, the anomalous gross moist stability mechanism induces positive precipitation anomalies within convective regions. The importance of variation in gross moist stability, which is likely to differ among climate models, is suggested as a potential factor causing discrepancies in the predicted regional tropical precipitation changes.
\end{abstract}

\section{Introduction}

In simulations of global warming by climate models (e.g., Boer et al. 2000a; Dai et al. 2001b; Delworth and Knutson 2000; Held and Soden 2000; Houghton et al. 2001; Meehl et al. 2000; Mitchell et al. 2000; Lucarini and Russell 2002; Washington et al. 2000; Watterson and Dix 1999; Yonetani and Gorden 2001), although the amplitudes of the climate changes vary, there is consensus that the atmosphere becomes warmer and more moist in response to anthropogenic increases in greenhouse gases (Houghton et al. 2001). On a regional scale, however, the simulations exhibit little agreement with each other, particularly in terms of tropical precipitation changes (e.g., Allen and Ingram 2002; Boer et al. 2000a; Dai et al 2001a; Douville et al. 2002; Houghton et al. 2001; Meehl et al. 2000; Roeckner et

\footnotetext{
* Institute of Geophysics and Planetary Physics, University of California, Los Angeles, Contribution Number 6100.
}

Corresponding author address: Dr. Chia Chou, Research Center for Environmental Change, Academia Sinica, Taipei 115, Taiwan. E-mail: chia@earth.sinica.edu.tw al. 1999; Williams et al. 2001). While the radiative forcing induced by the increases of greenhouse gases is relatively uniform in space, the corresponding tropical precipitation changes exhibit large variations, with both positive and negative rainfall anomalies. These changes in the climate of tropical deep-convection zones involve complex moist dynamical feedbacks and have received little analysis. Here we aim to determine the principle mechanisms that induce anomalous tropical precipitation with the increase of greenhouse gases.

To study the mechanisms that induce anomalous precipitation in a slightly simpler case, an atmospheric model coupled with a mixed layer ocean with equilibrium-doubled $\mathrm{CO}_{2}$ experiments is used. Climate models coupled with a mixed layer ocean capture many features of global warming in doubled $\mathrm{CO}_{2}$ experiments, including the pattern of positive and negative anomalous precipitation (Jin et al. 2001; Meehl et al. 2000; Watterson et al. 1997). The simulations give us initiating mechanisms before the ocean feedbacks that occur in fully coupled atmosphere-ocean general circulation model (GCMs). A climate model of intermediate complexity (Neelin and Zeng 2000; Chou et al. 2001) is used to permit the analysis of these mechanisms. 
A review of the model and a detailed description of the experiment design is given in section 2. Section 3 discusses the climate changes due to the doubled $\mathrm{CO}_{2}$ in the control experiments. Before examining the possible processes inducing anomalous precipitation, budgets of moisture and energy are analyzed in section 4. Based on the budget analysis, we postulate several mechanisms that are responsible for the tropical precipitation changes in section 5. Tests of these mechanisms are presented in section 6 , followed by the discussion and conclusions.

\section{The model and experiment design}

\section{a. The model}

To examine mechanisms that determine the anomalous tropical precipitation induced by global warming, a coupled ocean-atmosphere-land model of intermediate complexity (Neelin and Zeng 2000; Zeng et al. 2000, hereafter ZNC) with prescribed divergence of ocean heat transport ( $Q$ flux) is used. Based on the analytical solutions derived from the Betts-Miller moist convective adjustment scheme (Betts and Miller 1993), typical vertical structures of temperature, moisture, and winds for deep convection are used as leading basis functions for a Galerkin expansion (Neelin and Yu 1994; Yu and Neelin 1994). The atmospheric model constrains the flow by quasi-equilibrium thermodynamic closures and is referred to as the quasi-equilibrium tropical circulation model with a single vertical structure of temperature and moisture for deep convection (QTCM1). Because the basis functions are based on vertical structures associated with convective regions, these regions are expected to be well represented and similar to a GCM with the Betts-Miller moist convective adjustment scheme. Far from convective regions, QTCM1 is a highly truncated Galerkin representation equivalent to a two-layer model. A cloud-radiation scheme (Chou and Neelin 1996; ZNC), simplified from the full radiation schemes (Harshvardhan et al. 1987; Fu and Liou 1993), is included. In this scheme, deep and cirrocumulus/cirrostratus cloud fraction is estimated by an empirical parameterization (Chou and Neelin 1999). An intermediate land surface model (ZNC) is used to simulate interaction between the atmosphere and land surface. This model simulates processes such as evapotranspiration and surface hydrology in a single land surface layer for calculating energy and water budgets. Soil moisture is balanced by precipitation, evaporation, surface runoff, and ground runoff. This model does not include snow and sea ice feedback, leading to some caveats that will be discussed in the next section. In this study, QTCM1 version 2.3 is used. The main improvement in the model physics is the inclusion of a simple ABL that assumes a steady-state, vertically homogeneous mixed layer with a fixed height (Stevens et al. 2002). We note that in the QTCM1 radiation code (Chou and Neelin 1996), $\mathrm{CO}_{2}$ impacts are calculated from the Harshvardhan et al. (1987) GCM longwave code for clear skies and various cloud types as a linearized function of temperature and water vapor. This results in a table of flux coefficients used in the model runs. The radiation perturbation is a weakly nonlinear approximation to the full radiative calculation, but is less detailed.

\section{b. Experiment design}

In a pair of standard global warming experiments, a 40-yr average of the current climate of the control run is compared with a similar experiment that has a doubled $\mathrm{CO}_{2}$ concentration. After diagnosis of these runs, a set of hypothesis-testing experiments is conducted. To ensure that the differences are due to greenhouse forcing, we ran a new control experiment (normal $\mathrm{CO}_{2}$ ) with the specified effect as well as a doubled $\mathrm{CO}_{2}$ experiment and considered differences between this pair. For instance, to examine effects of the horizontal transport of moisture, its climatology obtained from the standard control run was used for both the normal and the doubled $\mathrm{CO}_{2}$ experiments. The differences between these two runs were compared to the differences between the standard experiments with the normal and the doubled $\mathrm{CO}_{2}$ so that the effect of the horizontal transport of moisture could be estimated. In order to identify how the doubled $\mathrm{CO}_{2}$ forcing affects the atmosphere initially and produces anomalous precipitation, an experiment with modified tropospheric temperature in the calculation of CAPE is used to create similar response of climate change in precipitation and other variables. Then, experiments designed to suppress a specified effect were used to examine mechanisms that affect tropical precipitation, and the results are compared to the standard experiments so that the importance of the specified effect on tropical precipitation can be estimated.

\section{Control runs}

Figure 1 shows differences in precipitation between the standard experiments with an equilibrium-doubled $\mathrm{CO}_{2}$ and the normal $\mathrm{CO}_{2}$ and 330 ppmv. The model precipitation anomalies with a global average of $23 \mathrm{~mm}$ $\mathrm{yr}^{-1}$ are comparable in magnitude to those found in many other doubled $\mathrm{CO}_{2}$ experiments done by GCMs, although spatial patterns tend to differ (e.g., Allen and Ingram 2002; Douville et al. 2002; Houghton et al. 2001; Meehl et al. 2000; Semenov and Bengtsson 2002). The largest changes in precipitation occur within $30^{\circ} \mathrm{S}-$ $30^{\circ} \mathrm{N}$, with seasonal variation following the seasonal movement of convection zones. The positive precipitation anomalies are often found within deep convective regions, while the negative precipitation anomalies tend to appear over the margins of convective regions. Since mechanisms for inducing the anomalous precipitation do not depend significantly on season, we only present 
(a) Prec Diff (DJF): varied cld (40 year ovg)

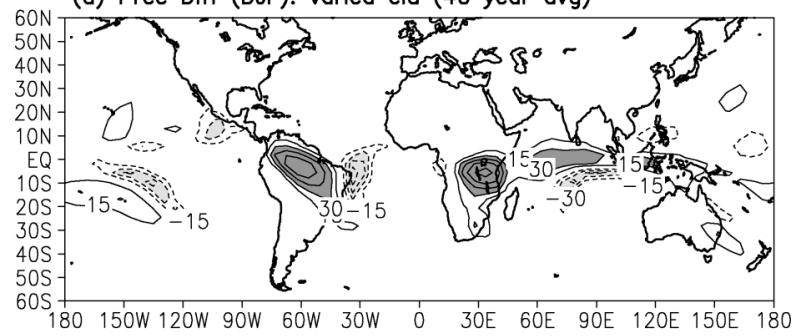
(b) JJA

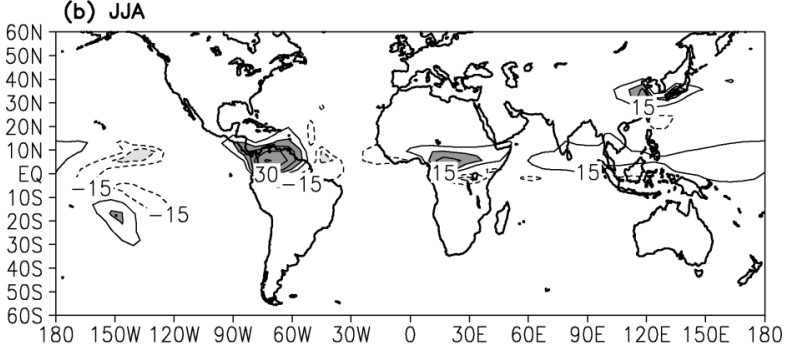
(c) ANN

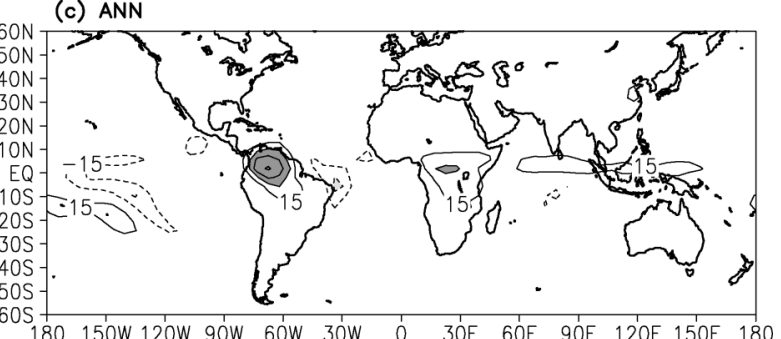

FIG. 1. Precipitation differences between the experiments with an equilibrium doubled $\mathrm{CO}_{2}$ and the normal $\mathrm{CO}_{2}$ at $330 \mathrm{ppmv}$ for 40 yr averages: (a) DJF, (b) JJA, and (c) annual climatology. Contour interval is $15 \mathrm{~W} \mathrm{~m}^{-2}$. Dark shading is above $30 \mathrm{~W} \mathrm{~m}^{-2}$ and light shading is below $-30 \mathrm{~W} \mathrm{~m}^{-2}$. Precipitation is given in $\mathrm{W} \mathrm{m}^{-2}$ for comparison to energy budgets. Divide by 28 to obtain $\mathrm{mm}^{\text {day }}{ }^{-1}$.

the December-February (DJF) season in subsequent figures for brevity.

To examine the importance of cloud-radiative feedback, we suppress spatial and time variations of cloud cover by specifying the tropical average from the control run as a constant for each cloud type (deep-convective clouds, cirrus, and stratus) in the radiation code. A normal $\mathrm{CO}_{2}$ experiment with this constant cloud cover is then compared to a doubled $\mathrm{CO}_{2}$ experiment with the same constant cloud cover to see doubled $\mathrm{CO}_{2}$ impacts in the absence of any cloud-radiative feedback (Fig. 2). The patterns of the anomalous precipitation in Fig. 2a are similar to those in Fig. 1a, with slightly heavier precipitation over land for the constant cloud-cover experiments. This implies that the cloud-radiative feedback is not a dominant effect in inducing anomalous precipitation in this model, even though the associated global cloud-radiative forcing at the top of the atmosphere has a similar amplitude $\left(\sim 1 \mathrm{Wm}^{-2}\right)$ to other studies (e.g., Meehl et al. 2000). Thus, for simplicity, experiments with constant cloud cover are used in this study to examine mechanisms that are responsible for anomalous precipitation. (a) Prec Diff (DJF): fixed cld (40 year ovg)

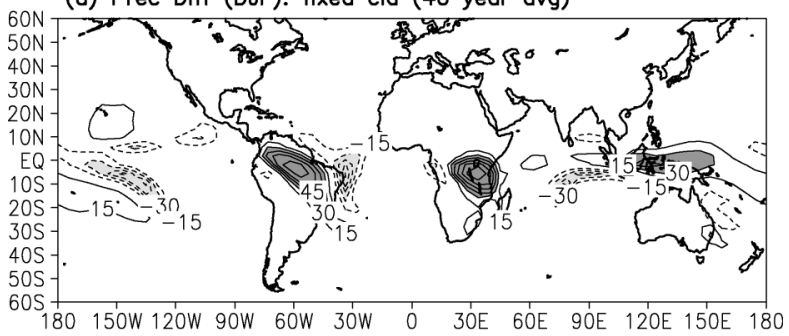

(b) Ts Diff

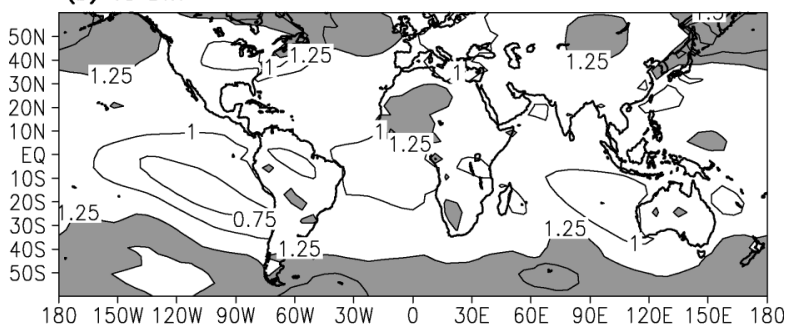

(c) That Diff

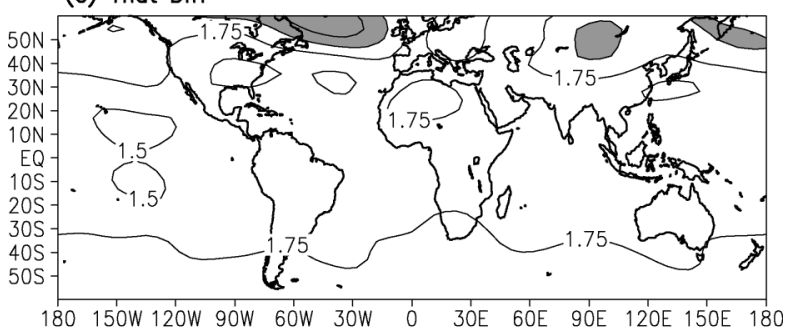

(d) qhat Diff

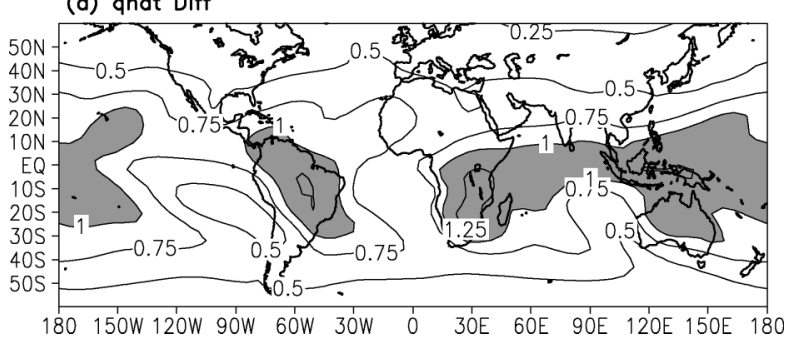

FIG. 2. As in Fig. 1 except for experiments with constant cloud cover. Differences in DJF for (a) precipitation, (b) surface temperature, (c) temperature integrated over the troposphere, and (d) moisture integrated over the troposphere. The moisture is in temperature units with latent heat per unit mass divided by specific heat capacity, $L / C_{p}$, absorbed. Contour interval for (a) is $15 \mathrm{~W} \mathrm{~m}^{-2}$ with dark shading above $30 \mathrm{~W} \mathrm{~m}^{-2}$ and light shading below $-30 \mathrm{~W} \mathrm{~m}^{-2}$. Contour interval for (b)-(d) is $0.25^{\circ} \mathrm{C}$ with shading above $1.25^{\circ} \mathrm{C}$ for (b), $2^{\circ} \mathrm{C}$ for $(\mathrm{c})$, and $1^{\circ} \mathrm{C}$ for $(\mathrm{d})$.

Figure $2 b$ shows changes of the surface temperature in DJF. The tropical warming is between $0.5^{\circ}$ and $1.5^{\circ} \mathrm{C}$, with smaller changes over the Pacific cold tongue and larger changes at higher latitudes. The surface temperature change is somewhat weak compared to other results, such as those in Douville et al. (2002), Houghton et al. (2001), and Meehl et al. (2000). Weaker warming may be associated with the lack of sea ice feedback resulting in smaller surface temperature changes at higher latitudes than in a GCM (e.g., Houghton et al. 2001; Meehl et al. 2000). This may also be due in part to lapse-rate effects 
(Hansen et al. 1997). The approximate moist adiabatic profile prescribed in QTCM1 may have a smaller lapse rate than in GCM global warming experiments (Houghton et al. 2001; Santer et al. 2000; Tett et al. 1996). This would tend to create an overestimate of longwave cooling to space for a given surface warming in QTCM1. A sensitivity test is discussed in section 6 .

The changes in air temperature integrated through the troposphere (Fig. 2c) are around $1.75^{\circ} \mathrm{C}$. There is less spatial variation than in surface temperature, although temperatures are slightly warmer at higher latitudes. In the doubled $\mathrm{CO}_{2}$ environment, the atmosphere becomes moist over most regions (Fig. 2d). In comparison with air temperature, changes in the tropospheric integrated moisture have a relatively larger meridional gradient, meaning that the increase in moisture is greater in the Tropics than in higher latitudes. In the Tropics, the maximum changes in vertically integrated moisture are over convective regions, while the minimum changes are over the cold tongue.

In the doubled $\mathrm{CO}_{2}$ experiment, the radiative forcing due to the increase of greenhouse gases is about $5 \mathrm{~W}$ $\mathrm{m}^{-2}$ in clear skies, and $3 \mathrm{~W} \mathrm{~m}^{-2}$ in convection zones. In the constant cloud cover experiment shown in Fig. 2 , the radiative forcing is approximated as uniform in space (not shown). However, the response of the model to this uniform forcing, in terms of precipitation and moisture, varies strongly with space (Fig. 2). How the model responds to the uniform forcing to produce the spatially varying response presents an interesting question. In the following sections, we examine possible mechanisms responsible for these changes associated with global warming.

\section{Budgets of moisture and energy}

\section{a. The moisture equation}

To understand mechanisms that determine variations in precipitation in the doubled $\mathrm{CO}_{2}$ experiments, the moisture budget equation is first examined. The moisture equation, integrated vertically, can be written as

$$
\partial_{t}\langle q\rangle+\langle\mathbf{v} \cdot \nabla q\rangle+\left\langle\omega \partial_{p} q\right\rangle=\left\langle Q_{q}\right\rangle+\frac{g}{p_{T}} E,
$$

where $E$ is evaporation, $\omega$ is pressure velocity, $\mathbf{v}$ is horizontal velocity, $g$ is gravity, and \langle\rangle denotes vertical averaging over the troposphere with $p_{T}$ as the depth of troposphere. The specific humidity $q$ is in energy units by absorbing the latent heat per unit mass, $L$. The moisture sink $\left\langle Q_{q}\right\rangle$ is related to precipitation $P$ by

$$
-\left\langle Q_{q}\right\rangle=\frac{g}{p_{T}} P
$$

Constrained by quasi-equilibrium convective closures,

$$
\left\langle\omega \partial_{p} q\right\rangle=-M_{q} \boldsymbol{\nabla} \cdot \mathbf{v}_{\mathbf{1}},
$$

where $\mathbf{v}_{\mathbf{1}}$ is the wind component associated with baro- clinic structure under convective quasi-equilibrium constraints. Here, $M_{q}$ is the gross moisture stratification (Neelin and Yu 1994; Yu et al. 1998) and is given by

$$
M_{q}=\left\langle\Omega \partial_{p} q\right\rangle \text {. }
$$

In convective regions, $M_{q}$ measures the basic-state moisture available for precipitation, $\Omega(p)$ is the vertical structure of vertical velocity from the baroclinic wind, and

$$
\omega(x, y, p, t)=-\Omega(p) \boldsymbol{\nabla} \cdot \mathbf{v}_{\mathbf{1}}(x, y, t) .
$$

Note that $\boldsymbol{\nabla} \cdot \mathbf{v}_{\mathbf{1}}>0$ indicates low-level convergence and upper-level divergence. Here, $\Omega(p)$ is positive, so $M_{q}$ is positive as well. From (1)-(5), the changes of the moisture budget integrated through the troposphere in QTCM1 for differences between two experiments in a statistically steady state can be approximately written as

$P^{\prime} \approx \frac{p_{T}}{g}\left(\bar{M}_{q} \boldsymbol{\nabla} \cdot \mathbf{v}_{\mathbf{1}}^{\prime}+M_{q}^{\prime} \boldsymbol{\nabla} \cdot \overline{\mathbf{v}}_{\mathbf{1}}-\langle\mathbf{v} \cdot \boldsymbol{\nabla} q\rangle^{\prime}\right)+E^{\prime}$,

where ( ) denotes averaged variables in the experiment with normal $\mathrm{CO}_{2}$, and ( )' represents the changes due to the effect of doubled $\mathrm{CO}_{2}$. Second-order terms in $M_{q}^{\prime} \boldsymbol{\nabla} \cdot \mathbf{v}_{\mathbf{1}}^{\prime}$ and changes in transients of this quantity are neglected for the tropical analysis presented here.

Figure 3 shows the horizontal distributions of the terms on the rhs of (6) in DJF. The pattern of the first term on the rhs of (6) (Fig. 3a) is very similar to the anomalous precipitation in Fig. 2a, and its amplitude is about $70 \%$ of the anomalous precipitation in Fig. $2 \mathrm{a}$. This implies that $\bar{M}_{q} \boldsymbol{\nabla} \cdot \mathbf{v}_{\mathbf{1}}^{\prime}$ is the dominant term in determining the anomalous precipitation. However, the effect of $\bar{M}_{q} \boldsymbol{\nabla} \cdot \mathbf{v}_{\mathbf{1}}^{\prime}$ is largely a feedback with $\boldsymbol{\nabla} \cdot \mathbf{v}_{\mathbf{1}}^{\prime}$ reacting to other effects (see discussion in section $4 \mathrm{~b}$ ). The second term on the right hand side of (6) has a clear positive contribution to precipitation over convective regions since moisture increases $\left(M_{q}^{\prime}>0\right)$ over convective regions $\left(\boldsymbol{\nabla} \cdot \overline{\mathbf{v}}_{\mathbf{1}}>0\right)$. Outside convective regions, $M_{q}^{\prime} \boldsymbol{\nabla} \cdot \overline{\mathbf{v}}_{\mathbf{1}}$ is negative but small since both amplitudes of $M_{q}^{\prime}$ and $\boldsymbol{\nabla} \cdot \overline{\mathbf{v}}_{1}$ are small. The third term is the horizontal advection of moisture integrated through the troposphere. In the Tropics, negative values of $-\langle\mathbf{v} \cdot \nabla q\rangle^{\prime}$ are found over the margins of convective regions, which indicates the transport of dry air into convective regions from nonconvective regions. The evaporation term (Fig. $3 \mathrm{~d}$ ) is relatively small, so it can be neglected for the first-order approximation in the moisture budget. Overall, over the positive anomalous precipitation regions, $\bar{M}_{q} \boldsymbol{\nabla} \cdot \mathbf{v}_{1}^{\prime}$ contributes $70 \%$ of the anomalous precipitation and $M_{q}^{\prime} \boldsymbol{\nabla} \cdot \overline{\mathbf{v}}_{\mathbf{1}}$ contributes the remaining $30 \%$. Over the negative anomalous precipitation regions, both $\bar{M}_{q} \boldsymbol{\nabla} \cdot \mathbf{v}_{\mathbf{1}}^{\prime}$ and $\langle\mathbf{v} \cdot \nabla q\rangle^{\prime}$ contribute to the anomalous precipitation.

\section{b. The energy equation}

Based on the moisture budget equation, $\bar{M}_{q} \boldsymbol{\nabla} \cdot \mathbf{v}_{\mathbf{1}}^{\prime}$ is the primary term contributing to the anomalous precip- 
(a) Mqm*diva (DJF): fixed cld (40 year avg)

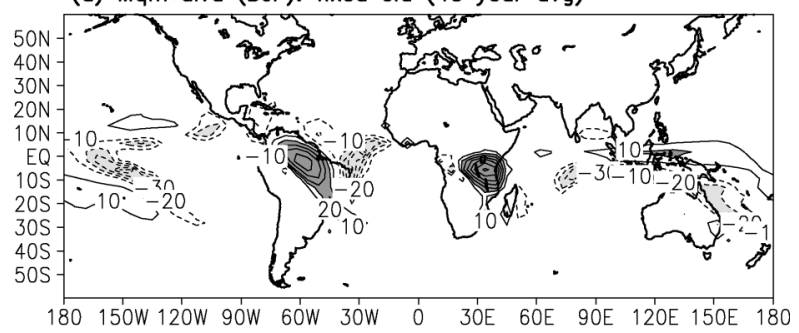

$180150 \mathrm{~W} 120 \mathrm{~W} 90 \mathrm{~W}$
(b) Mqa*Divm

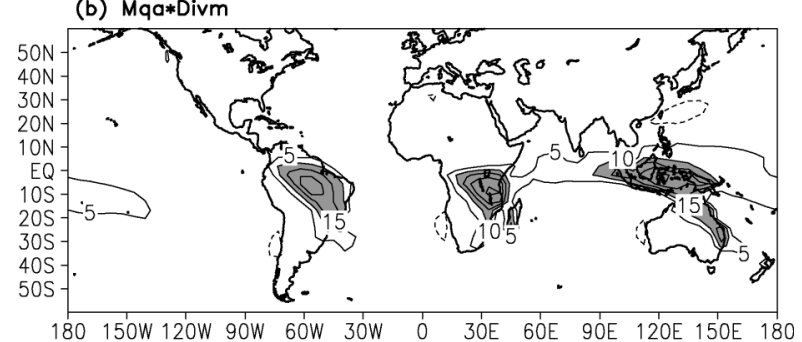

(c) -odvq1 Diff

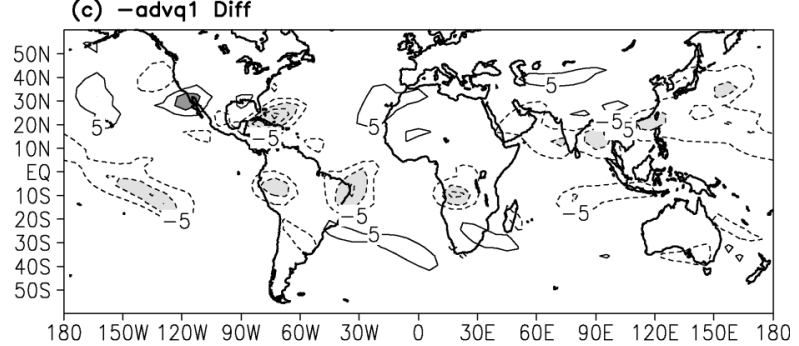

(d) Evap Diff

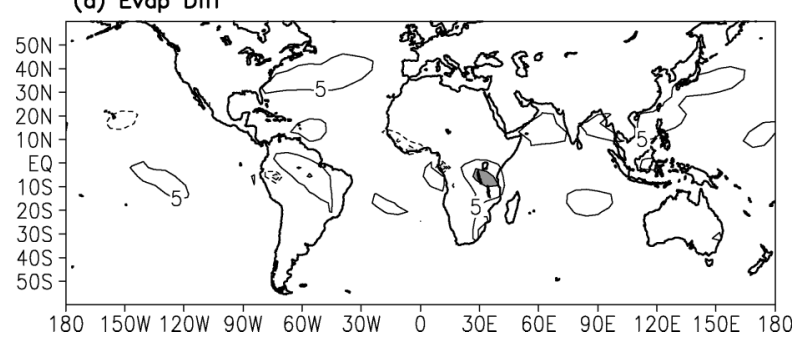

FIG. 3. As in Fig. 2 except for moisture budget terms (a) $\left(\bar{M}_{q} \boldsymbol{\nabla} \cdot \mathbf{v}_{\mathbf{1}}^{\prime}\right) p_{T} / g$,(b) $\left(M_{q}^{\prime} \boldsymbol{\nabla} \cdot \overline{\mathbf{v}}_{\mathbf{1}}\right) p_{T} / g$, (c) $-\langle\mathbf{v} \cdot \boldsymbol{\nabla} q\rangle^{\prime} p_{T} / g$, and (d) evaporation. Contour interval is $10 \mathrm{~W} \mathrm{~m}^{-2}$ with dark shading above $20 \mathrm{~W}$ $\mathrm{m}^{-2}$ and light shading below $-20 \mathrm{~W} \mathrm{~m}^{-2}$ for (a). Contour interval is $5 \mathrm{~W} \mathrm{~m}^{-2}$ with dark shading above $10 \mathrm{~W} \mathrm{~m}^{-2}$ and light shading below $-10 \mathrm{~W} \mathrm{~m}^{-2}$ for (b)-(d).

itation. In order to understand the factors that cause $\boldsymbol{\nabla} \cdot \mathbf{v}_{\mathbf{1}}^{\prime}$, the energy budget equation is used. The vertically integrated moist static energy equation can be written as

$$
\partial_{t}\langle q+T\rangle+\langle\mathbf{v} \cdot \nabla(q+T)\rangle+\left\langle\omega \partial_{p}(q+T)\right\rangle=\frac{g}{p_{T}} F^{\text {net }},
$$

where $T$ is atmospheric temperature that absorbs the heat capacity at constant pressure, $C_{p}$, and $F^{\text {net }}$ is defined as the net energy input into the atmospheric column:

$$
\begin{aligned}
F^{\text {net }}= & S_{t}^{\downarrow}-S_{t}^{\uparrow}-S_{s}^{\downarrow}+S_{s}^{\uparrow}-R_{t}^{\uparrow}-R_{s}^{\downarrow}+R_{s}^{\uparrow} \\
& +E+H .
\end{aligned}
$$

Here, subscripts $s$ and $t$ on the solar $\left(S^{\downarrow}\right.$ and $\left.S^{\uparrow}\right)$ and longwave $\left(R^{\uparrow}\right.$ and $\left.R^{\downarrow}\right)$ radiative terms denote surface and model top, $R_{t}^{\downarrow} \approx 0$ has been used, and $H$ is the sensible heat flux. Under quasi-equilibrium convective closures,

$$
\left\langle\omega \partial_{p}(q+T)\right\rangle=\left\langle\omega \partial_{p} h\right\rangle=-M \nabla \cdot \mathbf{v}_{\mathbf{1}},
$$

where $h$ is the moist static energy, and $M$ is the gross moist stability (Neelin and Yu 1994; Yu et al. 1998) and is defined by

$$
M=\left\langle\Omega\left(-\partial_{p} h\right)\right\rangle .
$$

In convective regions, $M$ represents static stability for large-scale motions. From (7), using the same time-average definitions and approximations as in (6), changes in the vertically integrated energy budget equation can be written as

$$
\frac{p_{T}}{g}\left(\bar{M} \boldsymbol{\nabla} \cdot \mathbf{v}_{\mathbf{1}}^{\prime}+M^{\prime} \boldsymbol{\nabla} \cdot \overline{\mathbf{v}}_{\mathbf{1}}\right)=F^{\mathrm{net}^{\prime}}-\frac{p_{T}}{g}\langle\mathbf{v} \cdot \boldsymbol{\nabla}(q+T)\rangle^{\prime} .
$$

While (11) is a diagnostic budget, experience with related tropical problems (e.g., Neelin and Held 1987; Su and Neelin 2002) suggests that $\boldsymbol{\nabla} \cdot \mathbf{v}_{\mathbf{1}}^{\prime}$ often reacts to balance casual mechanisms that act via the other terms. Thus, it can be useful to examine the budget terms from this point of view.

Figure 4 shows the DJF horizontal distributions of the terms of (11) that tend to create $\boldsymbol{\nabla} \cdot \mathbf{v}_{\mathbf{1}}^{\prime}$. Net energy input $F^{\text {net' }}$ is smaller than the other terms of (11) shown in Fig. 4, so it can be neglected as first-order approximation for this equilibrium greenhouse warming case. This may seem counterintuitive, since the initial cause of the warming is due to an imbalance in $F^{\text {net }}$ caused by greenhouse gas increases. Both the radiative forcing due to greenhouse gases and the temperature increases that balance this forcing have very large spatial scales. They thus tend to cancel, not only in the global average, but region by region. More importantly, the energy budget terms due to atmospheric transports can be large at the regional scale even though they cancel in the global average.

The other terms in Fig. 4 indicate that different mechanisms control $\boldsymbol{\nabla} \cdot \mathbf{v}_{\mathbf{1}}^{\prime}$ over convective regions and the margins of convective regions. Over convective regions, the first and second terms on the rhs of (11) (Figs. 4c,d) are relatively small, so $\boldsymbol{\nabla} \cdot \mathbf{v}_{\mathbf{1}}^{\prime}$. can be estimated from

$$
\boldsymbol{\nabla} \cdot \mathbf{v}_{\mathbf{1}}^{\prime}=-\frac{M^{\prime}}{\bar{M}} \boldsymbol{\nabla} \cdot \overline{\mathbf{v}}_{\mathbf{1}} \cdot
$$

The changes in convergence due to doubled $\mathrm{CO}_{2}$ are induced by variations of the gross moist stability, $M^{\prime}$. Over convective regions, the values of $M^{\prime} \boldsymbol{\nabla} \cdot \mathbf{v}_{\mathbf{1}}^{\prime}$ are negative and $\bar{M}$ is positive, so $\boldsymbol{\nabla} \cdot \mathbf{v}_{\mathbf{1}}^{\prime}>0$ and the convergence is enhanced. By replacing $\boldsymbol{\nabla} \cdot \mathbf{v}_{\mathbf{1}}^{\prime}$ with (12), (6) can be rewritten as 
(a) Mm*diva (DJF): fixed cld (40 year ovg)

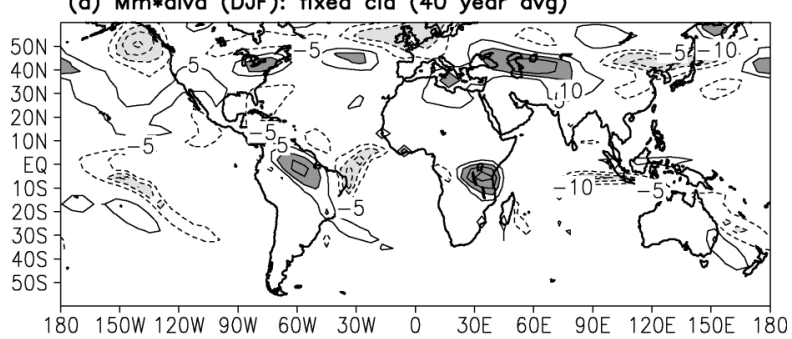

(b) Ma*Divm

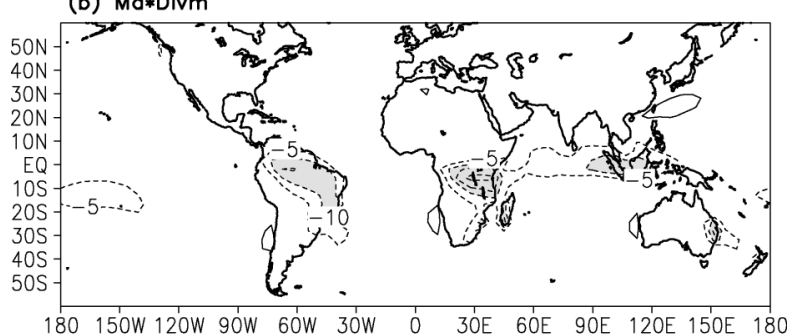

(c) $-\operatorname{adv}(T 1+q 1)$ Diff

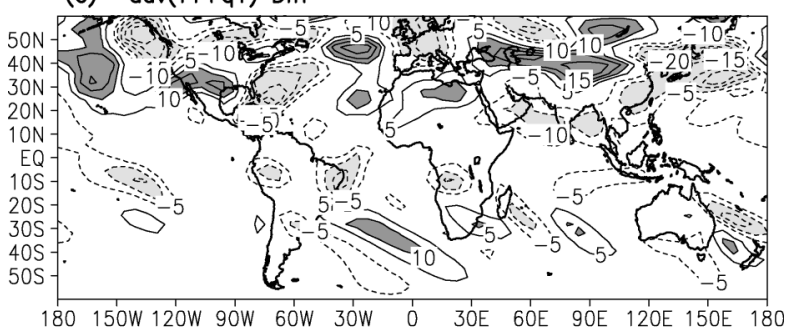

(d) Fnet Diff

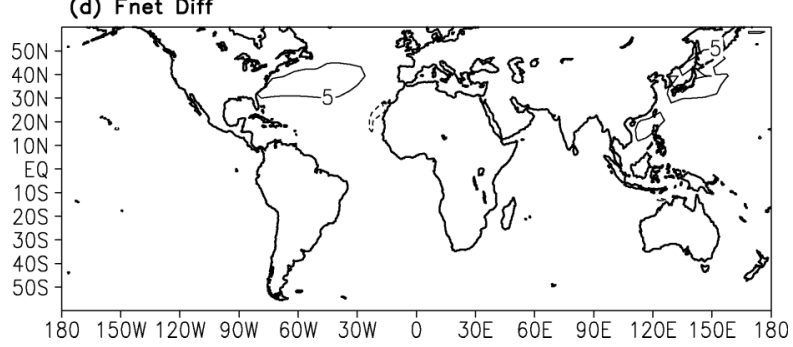

FIG. 4. As in Fig. 2 except for (a) $\left(\bar{M} \boldsymbol{\nabla} \cdot \mathbf{v}_{1}^{\prime}\right) p_{T} / g$, (b) $\left(M^{\prime} \boldsymbol{\nabla} \cdot \overline{\mathbf{v}}_{1}\right) p_{T} /$ $g$, (c) $-\langle\mathbf{v} \cdot \nabla(q+T)\rangle^{\prime} p_{T} / g$, and (d) $F^{\text {net }}$. Contour interval is $5 \mathrm{~W}$ $\mathrm{m}^{-2}$ with dark shading above $10 \mathrm{~W} \mathrm{~m}^{-2}$ and light shading below -10 $\mathrm{W} \mathrm{m} \mathrm{m}^{-2}$.

$$
P^{\prime}=\frac{p_{T}}{g} \boldsymbol{\nabla} \cdot \overline{\mathbf{v}}_{\mathbf{1}}\left[\frac{\bar{M}_{q}}{\bar{M}}\left(-M^{\prime}\right)+M_{q}^{\prime}\right]
$$

over convective regions since $-\langle\mathbf{v} \cdot \nabla q\rangle^{\prime}$ and $E^{\prime}$ are small over these areas. The anomalous precipitation over convective regions $\left(\boldsymbol{\nabla} \cdot \overline{\mathbf{v}}_{\mathbf{1}}>0\right)$ is determined by effects that induce the changes of $M$ and $M_{q}$. The first term on the rhs of (13) is a convergence feedback that will be discussed later as the "anomalous gross moist stability mechanism" in section 5b. The second term is a mechanism we refer to as the "direct moisture effect," which is the effect of the increased moisture on moisture convergence if the divergence term $\left(\boldsymbol{\nabla} \cdot \mathbf{v}_{\mathbf{1}}\right)$ does not change due to doubled $\mathrm{CO}_{2}$.

Unlike in convective regions, $-\langle\mathbf{v} \cdot \nabla(q+T)\rangle^{\prime}$ is the dominant effect in determining $\boldsymbol{\nabla} \cdot \mathbf{v}_{\mathbf{1}}^{\prime}$ in the margins of convective regions. Comparing Figs. $4 c$ and $3 c$ in the Tropics, $\langle\mathbf{v} \cdot \nabla T\rangle^{\prime}$ is relatively small and $\langle\mathbf{v} \cdot \nabla q\rangle^{\prime}$ dominates. Thus, $\boldsymbol{\nabla} \cdot \mathbf{v}_{\mathbf{1}}^{\prime}$ can be estimated by

$$
\boldsymbol{\nabla} \cdot \mathbf{v}_{\mathbf{1}}^{\prime}=-\frac{\langle\mathbf{v} \cdot \boldsymbol{\nabla} q\rangle^{\prime}}{\bar{M}} .
$$

This implies that the anomalous divergence is induced by the anomalous horizontal advection of moisture. Replacing $\boldsymbol{\nabla} \cdot \mathbf{v}_{\mathbf{1}}^{\prime}$ with (14) and noting that $M_{q}^{\prime} \boldsymbol{\nabla} \cdot \overline{\mathbf{v}}_{\mathbf{1}}$ is small outside convective regions, (6) can be rewritten as

$$
P^{\prime}=\frac{p_{T}}{g}\left(1+\frac{\bar{M}_{q}}{\bar{M}}\right)\left(-\langle\mathbf{v} \cdot \nabla q\rangle^{\prime}\right) .
$$

The precipitation over the margins of convective regions is affected not only by the horizontal advection of moisture, but also by the divergence anomalies that are induced by the feedback of the horizontal advection of moisture. The values of $-\langle\mathbf{v} \cdot \boldsymbol{\nabla} q\rangle^{\prime}$ are negative over the margins of convective regions, so the convection over these regions weakens due to the direct effect and the feedback of the horizontal transport of dry air into convective regions from nonconvection regions.

\section{Postulated mechanisms}

Based on the budget analysis that has been discussed in the previous section, two main mechanisms are responsible for the anomalous tropical precipitation. The first one we refer to as the "upped-ante mechanism" (see below), which is associated with the effect of $-\langle\mathbf{v} \cdot \nabla q\rangle^{\prime}$ on moisture gradients induced by differences between convective and nonconvective regions. This mechanism has been outlined in Neelin et al. (2003, hereafter NCS03), in which the relationship between its role in global warming and in remote impacts of El Niño are examined. Here we give a fuller presentation of its role in global warming, with comparison to other mechanisms. The second mechanism we term the anomalous gross moist stability mechanism, which is associated with the variation of the gross moist stability $(M)$ in convective regions. Several secondary mechanisms, such as cloud-radiative feedback, the variation of the gross moisture stratification $\left(M_{q}^{\prime}\right)$, and the evaporation feedback, also contribute slightly to the anomalous precipitation. All the mechanisms are discussed in the following sections.

\section{a. The upped-ante mechanism}

Figure 5 is a schematic diagram used to explain the upped-ante mechanism. Increased greenhouse gases tend to warm the atmosphere (Fig. 2c). To maintain positive $\mathrm{CAPE}$ in convective regions, $\mathrm{ABL}$ moisture tends to increase (Chiang and Sobel 2002), so the increased ABL moisture can compensate the warmer-tropospheric temperature. However, in nonconvective re- 


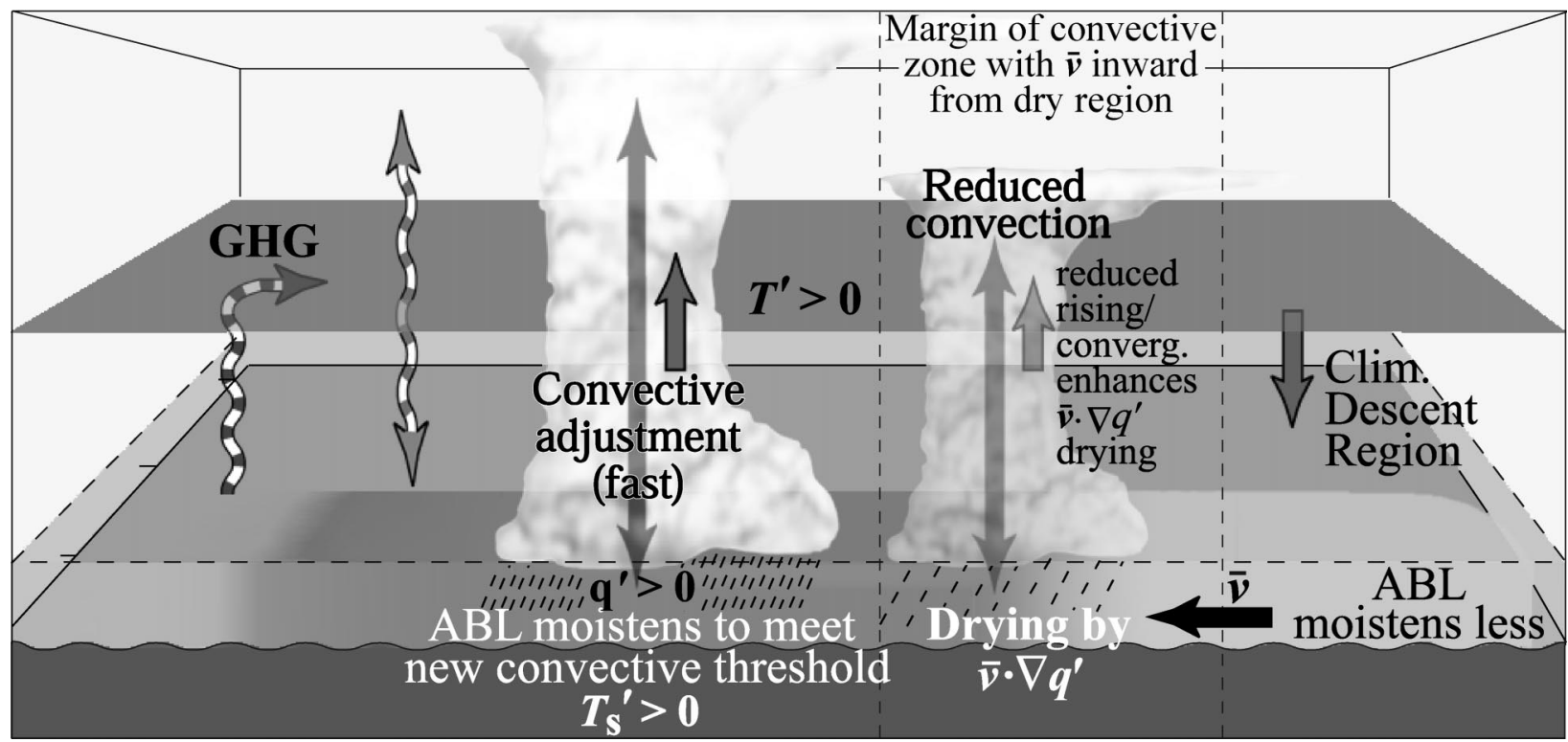

FIG. 5. A schematic diagram for the upped-ante mechanism (adapted from NCS03).

gions, the ABL moisture is determined by different balances and does not increase as much as it does in convective regions. This differing response to the warmer-tropospheric temperature induces a spatial pattern of the ABL moisture anomalies. Then inward flow associated with the climatological convection imports dry air from nonconvective regions to the margins of convective regions $\left(-\left\langle\overline{\mathbf{v}} \cdot \nabla q^{\prime}\right\rangle<0\right)$, so the atmosphere has smaller ABL moisture anomalies over the margins of convective regions than over the center of them. The margins of convective regions with less ABL moisture cannot sustain the original convection in the face of the new convective threshold in the doubled $\mathrm{CO}_{2}$ environment, so convection is reduced over the margins of convective regions. This process is analogous to a poker game, in which a player must meet the upped ante (sufficient $\mathrm{ABL}$ moisture) in order to continue playing the game (the convection), hence the term upped-ante mechanism. The center of convective regions with greater moisture supply by convergence can still meet the new "convective ante," so the convection is maintained. In other words, the ante is only relevant for regions that cannot supply sufficient ABL moisture to meet it.

The upped-ante mechanism has contributions from two terms in the moisture budget, as can be seen from (15). Based on (14), the import of dry air can also induce a subsidence anomaly. This mechanism is similar to one of "cooling tendencies" proposed by Su and Neelin (2002) for the ENSO-induced subsidence. The feedback associated with subsidence further reduces convection over the margins of convective regions. The subsidence associated with negative values of $\bar{M} \boldsymbol{\nabla} \cdot \mathbf{v}_{\mathbf{1}}^{\prime}$ in the Tropics (Fig. 4a) is well aligned with negative values of $-\langle\mathbf{v} \cdot \nabla q\rangle^{\prime}$ (Fig. 3c). This provides evidence that the subsidence is induced by $-\langle\mathbf{v} \cdot \nabla q\rangle^{\prime}$, and experiments in section $6 \mathrm{~b}$ confirm this. In (15), both the direct effect and the feedback of the horizontal transport of moisture reduce the precipitation over the margins of convective regions. Since $\bar{M}_{q}$ is larger than $\bar{M}$ (Yu et al. 1998), the feedback [the second term on the rhs of (15)] is larger in magnitude than the direct effect [the first term on the rhs of (15)] and greatly amplifies the reduction in precipitation.

The above discussion simplifies some processes that may potentially be part of the same mechanism. First, ABL temperature increases can also help to maintain CAPE in face of increased free-tropospheric temperature. However, horizontal ABL temperature gradients in a global warming simulation tend to be smaller than the moisture gradients we emphasize in our discussion. Second, we phrase our discussion in terms of CAPE as a measure of parcel buoyancy in convection, but one could equally use other measures of this. Third, convection affects and is affected by moisture above the subcloud layer, so the mechanism likely applies to changes in moisture and moisture advection through the lower troposphere.

\section{b. The anomalous gross moist stability mechanism}

In global warming, the moistened ABL reduces the gross moist stability $(M)$ so that convection is enhanced and precipitation becomes heavier in convective regions. This process is induced by the variation in gross moist stability, so it is termed the anomalous gross moist stability $\left(M^{\prime}\right)$ mechanism. Over convective regions, the $M^{\prime}$ mechanism is the dominant effect that contributes about $70 \%$ of the anomalous precipitation (Figs. $2 \mathrm{a}$ and $3 \mathrm{~b})$. When the atmosphere is moistened and the gross moist stability is reduced (not shown) in QTCM1 ac- 
cording to (13), the sign of the $M^{\prime}$ mechanism on precipitation is determined by the sign of $\boldsymbol{\nabla} \cdot \overline{\mathbf{v}}_{\mathbf{1}}$, since $\bar{M}_{q}$ and $\bar{M}$ are both positive and vary relatively little in the Tropics. Thus, the stronger the convection, the larger the enhancement of the convection. One might be tempted to refer to this colloquially as the "rich-get-richer mechanism." Due to the domination of the $M^{\prime}$ mechanism over convective regions, $M^{\prime} \boldsymbol{\nabla} \cdot \overline{\mathbf{v}}_{\mathbf{1}}$ in Fig. $4 \mathrm{~b}$ is well aligned with the positive value of $\bar{M}_{q} \boldsymbol{\nabla} \cdot \mathbf{v}_{1}^{\prime}$ in Fig. $3 \mathrm{a}$ and $P^{\prime}$ in Fig. 2a.

The gross moist stability, $M$, tends to depend on both low-level moisture and the maximum depth of convection (Yu et al. 1998). An increase of moisture in the lower troposphere reduces $M$, while an increase in the maximum level of deep convection increases it. Since the increase of low-level moisture also enhances convection and the associated maximum depth of convection, there is a strong cancellation between these two effects. Yu et al. (1998) show that $M$ is relatively constant in the Tropics because of this strong cancellation. Thus, $M^{\prime}$ varies with a very fine balance of these two strong effects. In their calculation, a maximum depth of convection determined by the assumption of equal moist static energy at cloud base and cloud top is used. However, the depth of convection may be less when considering entrainment. Yu et al. (1998) also used an approximation that neglects frictionally induced convergence in defining $M$. As a result of these factors, theories for $M^{\prime}$ are still poorly understood. The factors that determine $M$, including the maximum depth of convection, are likely to be sensitive to cumulus parameterizations, so the $M^{\prime}$ mechanism might vary among climate models. The uncertainty of determining $M^{\prime}$ can potentially induce different regional tropical precipitation changes among climate models.

\section{c. Secondary mechanisms}

\section{1) Cloud-Radiative Feedback}

Cloud-radiative feedback has two opposite effects on convection: a positive effect of longwave (infrared) cloud-radiative forcing and a negative effect of shortwave (solar) reflection by clouds (Kiehl 1994). The strength of the longwave cloud-radiative forcing is determined by cloud-top temperature, and in deep convective regions the shortwave and longwave contributions tend to partially cancel in QTCM1 as in other models (Cess et al. 1996). Comparing Figs. 1a and 2a, the anomalous precipitation over convective regions, especially over land, is heavier in the constant cloud experiments than in the experiments with varying cloudcover experiments. This is because in this QTCM1 version the negative feedback of the shortwave cloud-radiative forcing is slightly stronger than the longwave feedback. This effect is stronger over land because the land surface temperature response to cloud reflection of solar radiation is faster than the ocean mixed layer dur- ing the seasonal cycle. However, shortwave versus longwave effects are sensitive to the cloud-top height of deep clouds, as discussed in the sensitivity experiments in section 6d. Overall, the net cloud-radiative feedback associated with deep convection can be a slightly amplifying or reducing factor but it is not a primary cause of the precipitation anomalies.

\section{2) DiRECT MOISTURE EFFECT}

In (13), we refer to the second term on the right as the direct moisture effect, which contributes $30 \%$ of the positive anomalous precipitation over convective regions (Fig. 3b). Since it depends mainly on $M_{q}^{\prime}$, it can also be called the $M_{q}^{\prime}$ effect. Here $M_{q}$ is determined by low-level moisture only and its value is larger than $M$ (Yu et al. 1998). The value of $M_{q}$ is not sensitive to the maximum depth of convection, so the direct moisture effect is not expected to vary sensitively among models, although midlevel moisture treatment may have some impact. In the doubled $\mathrm{CO}_{2}$ environment, $M_{q}^{\prime}$ is positive everywhere due to the increase of atmospheric moisture, so the sign of the direct moisture effect on precipitation anomalies is determined by $\boldsymbol{\nabla} \cdot \overline{\mathbf{v}}_{\mathbf{1}}$. Over convective regions, that is $\boldsymbol{\nabla} \cdot \overline{\mathbf{v}}_{\mathbf{1}}>0$, the convection is augmented by the direct moisture effect, so precipitation is enhanced. Over nonconvective regions, since $M_{q}^{\prime}$ is a small positive value and $\boldsymbol{\nabla} \cdot \overline{\mathbf{v}}_{\mathbf{1}}$ is a small negative value, the direct moisture effect reduces the precipitation only slightly.

\section{3) THE $E^{\prime}$ EFFECT}

According to (6), variation in evaporation may also contribute to anomalous precipitation, but its effect is smaller compared to the others (Fig. 3). Over land, evaporation can be enhanced over convective regions by increased soil moisture resulting from heavy precipitation. However, the clouds associated with the heavy precipitation reflect more solar radiation, so both surface temperature and evaporation are reduced. The positive $E^{\prime}$ over land (Fig. 3d) implies that the effect of increased soil moisture is dominant in determining the sign of the $E^{\prime}$ effect. Figure $3 d$ shows that the $E^{\prime}$ effect enhances the positive precipitation anomalies by about $10 \%$ over the tropical land. The increase in evaporation over land reduces the surface temperature, so the increased land surface temperature resulting from global warming is somewhat reduced by the $E^{\prime}$ effect.

\section{Tests of main mechanisms}

The main mechanisms discussed in the previous section are mediated by the spatial variation of ABL moisture over convection zones in the warmer climate. Under quasi-equilibrium convective closure, convection tends to establish a link between tropospheric temperature and ABL moisture to maintain positive CAPE in convection 
zones (Chiang and Sobel 2002). Thus, we use the term "CAPE-mediated impacts" as shorthand for the effect associated with the variation of ABL moisture in response to tropospheric temperature changes in convection zones. We first test the CAPE-mediated impacts and compare the results to the doubled $\mathrm{CO}_{2}$ experiments. Then, the upped-ante mechanism and the $M^{\prime}$ mechanism are tested by suppressing the terms $-\langle\mathbf{v}$. $\boldsymbol{\nabla} q\rangle^{\prime}$ and $M^{\prime}$, respectively, so that the effect of each mechanism can be identified. We also conduct several sensitivity tests, so that caveats associated with the model parameterizations, such as the determination of cloud top and the vertical profile of the anomalous temperature can be examined. These can give us some insight into why climate change induced by the same global warming forcing differs in various climate models.

\section{a. CAPE-mediated impacts}

To test the role of mediation by CAPE in these processes, a change in tropospheric temperature is specified in the model only where it enters the convective parameterization. The specified temperature difference is a constant of a value similar to the tropical average change diagnosed from the doubled $\mathrm{CO}_{2}$ run. It does not directly affect radiation or other parameterizations, but it does affect CAPE. Thus, this is referred to as the CAPE experiment. Figure 6 shows the differences between the CAPE experiment and the control experiment with constant cloud cover. Overall, the pattern of anomalous precipitation is similar to the pattern in the doubled $\mathrm{CO}_{2}$ experiment (Fig. 2a). This implies that the CAPE-mediated effect indeed induces the anomalous tropical precipitation. The regions of negative precipitation anomalies are somewhat stronger, while the regions of positive precipitation anomalies are weaker, but the patterns correspond well to the doubled $\mathrm{CO}_{2}$ experiment. The pattern and amplitude of $T_{s}^{\prime}$ is similar to the doubled $\mathrm{CO}_{2}$ experiment, but with a slightly stronger meridional gradient. In the doubled $\mathrm{CO}_{2}$ experiment, the decrease in outgoing longwave radiation (OLR) induced by the $\mathrm{CO}_{2}$-longwave radiative feedback is balanced by the increase in OLR induced by the positive $\left\langle T^{\prime}\right\rangle$. In the CAPE experiment, on the other hand, the forcing directly modifies the tropospheric temperature associated with the calculation of CAPE in QTCM1, so it is not necessary for $\mathrm{CO}_{2}$-induced OLR reduction to be balanced by the increase in OLR induced by $\left\langle T^{\prime}\right\rangle$. Thus, $\left\langle T^{\prime}\right\rangle$ in Fig. 6c has only one-third the amplitude of $\left\langle T^{\prime}\right\rangle$ in the doubled $\mathrm{CO}_{2}$ experiment, and the increase in $\left\langle T^{\prime}\right\rangle$ in Fig. $6 \mathrm{c}$ is induced by the greenhouse effect of the positive $\left\langle q^{\prime}\right\rangle$ (Fig. 6d). Under the quasi-equilibrium convective closure, the CAPE-mediated effect increases the atmospheric moisture, that is $q^{\prime}>0$, to compensate for the effect of increased $\left\langle T^{\prime}\right\rangle$. Figure $6 \mathrm{~d}$ shows a similar pattern of $\left\langle q^{\prime}\right\rangle$ to the doubled $\mathrm{CO}_{2}$ experiment (Fig. 2d), but with slightly larger amplitude.

The CAPE-mediated effect enhances moisture over convective regions, so $M$ decreases due to the low-level moisture effect. The $M^{\prime}$ mechanism then induces the positive precipitation anomalies over convective regions. Thus, the stronger the original convection, the greater the enhancement of precipitation. However, the CAPE-mediated effect does not influence nonconvective regions, which are controlled by different balances. These different CAPE-mediated impacts produce $\nabla q^{\prime}$, and then the upped-ante mechanism creates negative precipitation anomalies over the margins of convective regions. The surface temperature is also increased by the longwave radiative feedback of the enhanced moisture. Thus, the uneven spatial distribution of CAPEmediated impacts over convective regions is the first step in inducing anomalous tropical precipitation.

\section{b. The upped-ante mechanism}

To suppress the effect of the upped-ante mechanism, as initially discussed in NCS03, the climatology of $\langle\mathbf{v} \cdot \nabla q\rangle$, obtained from the standard experiment with normal $\mathrm{CO}_{2}$, is used in experiments with normal $\mathrm{CO}_{2}$ and doubled $\mathrm{CO}_{2}$ so that $\langle\mathbf{v} \cdot \nabla q\rangle^{\prime}=0$. The normal $\mathrm{CO}_{2}$ experiment is rerun to ensure that any impacts of the $\langle\mathbf{v} \cdot \nabla q\rangle$ specification are not included in the anomalies, although the changes to the climatology of the control are modest (not shown). Figure 7 shows the differences in DJF precipitation between normal and doubled $\mathrm{CO}_{2}$ experiments when $\langle\mathbf{v} \cdot \nabla q\rangle$ is fixed. In comparison with Fig. $2 \mathrm{a}$, the strong negative precipitation anomalies are substantially reduced in all the main regions, as expected since they correspond to negative $-\langle\mathbf{v} \cdot \nabla q\rangle^{\prime}$ in Fig. 3c. This confirms that the upped-ante mechanism does strongly influence the negative anomalous precipitation over the margins of convective regions.

Some additional features may be noted in this experiment. Small negative values of precipitation anomalies still remain in some regions in Fig. 7. These appear to be associated with the same moisture gradients as in the upped-ante mechanism, but with diffusion acting in place of the suppressed $\langle\mathbf{v} \cdot \nabla q\rangle^{\prime}$. Over the strong convective regions, the rainfall anomalies are larger than in Fig. 2a. This occurs because $-\langle\mathbf{v} \cdot \nabla q\rangle^{\prime}$ has a small negative impact on convection over convective regions (Fig. 3c), even though $-\langle\mathbf{v} \cdot \nabla q\rangle^{\prime}$ has been neglected when deriving (13). Thus, when $\langle\mathbf{v} \cdot \nabla q\rangle^{\prime}$ is suppressed, $\bar{M}_{q} \boldsymbol{\nabla} \cdot \mathbf{v}_{\mathbf{1}}^{\prime}$ is enhanced over convective regions as well as precipitation anomalies. The enhanced convection increases atmospheric moisture and then $M_{q}$, so precipitation is further enhanced by the direct moisture effect, $M_{q}^{\prime} \boldsymbol{\nabla} \cdot \overline{\mathbf{v}}_{\mathbf{1}}$. We also repeated this experiment in cases with interactive cloud cover and obtained the same strong reduction in negative precipitation anomalies.

\section{c. The $M^{\prime}$ mechanism}

The gross moist stability, $M$, is determined by the difference of the dry static stability, $M_{s}$, and the gross 
(a) Prec Diff (DJF): fixed cld and Qc-1.5(40 year avg)

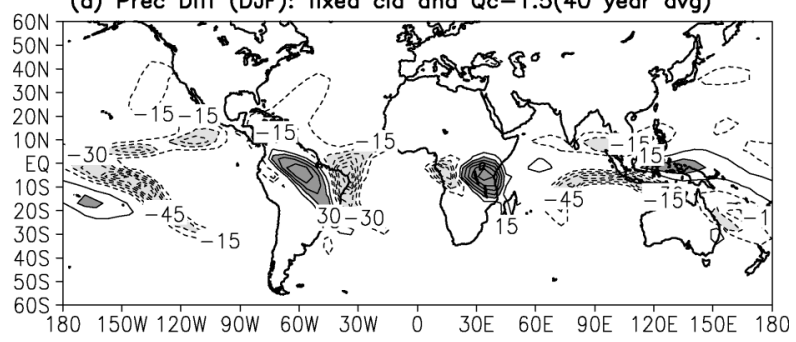

(b) Ts Diff

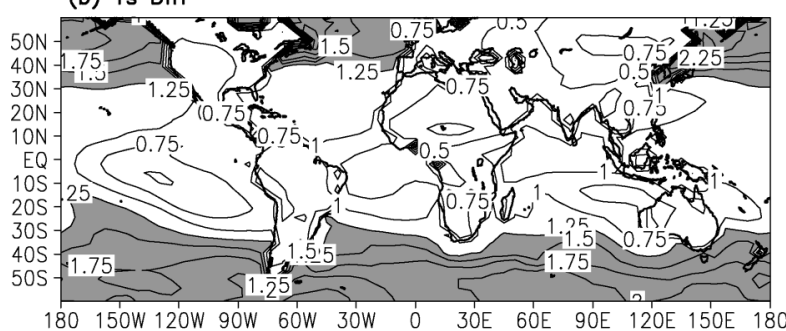

(c) That Diff

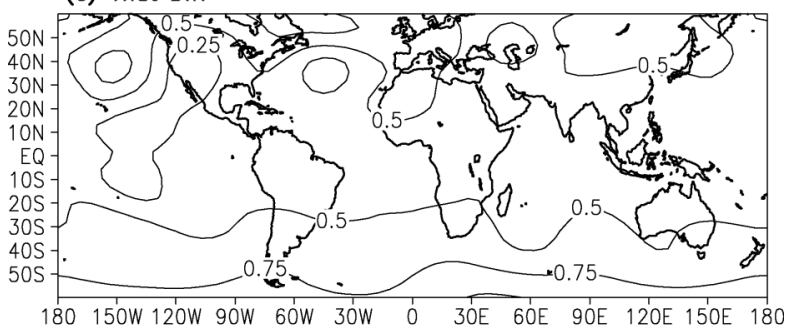

(d) qhat Diff

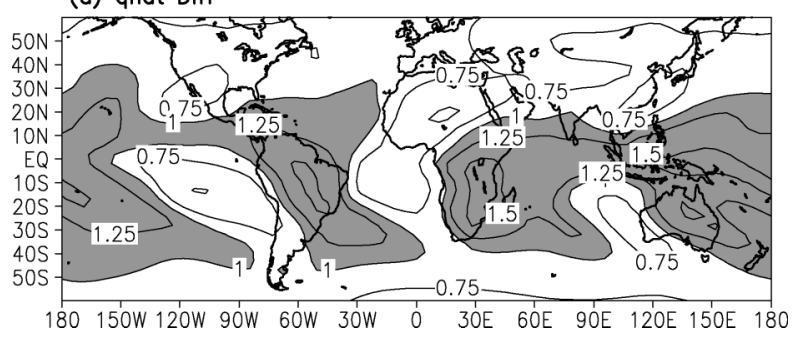

FIG. 6. As in Fig. 2 except for the CAPE experiments.

moisture stratification, $M_{q}$, that is $M=M_{s}-M_{q}$. Also, $M^{\prime}=0$ when $M_{s}^{\prime}=M_{q}^{\prime}$. To test the $M^{\prime}$ mechanism, we artificially set $M_{s}^{\prime}=M_{q}^{\prime}$ in convective regions, and ran normal and doubled $\mathrm{CO}_{2}$ experiments. Figure 8 shows the difference in DJF precipitation between these. A great reduction in the amplitude of precipitation anomalies over strong convective regions is found, which provides evidence that the $M^{\prime}$ mechanism is the leading contribution to the amplitude of the positive precipitation anomalies over convective regions.

Regarding the remaining precipitation anomalies in Fig. 8, with the $M^{\prime}$ mechanism suppressed, the direct moisture effect, $M_{q}^{\prime} \boldsymbol{\nabla} \cdot \overline{\mathbf{v}}_{\mathbf{1}}$, becomes the main remaining factor inducing anomalous precipitation over convective regions. The pattern of $M_{q}^{\prime}$ is close to $-M^{\prime}$ in convection regions, so the pattern of positive precipitation shown in Fig. 8 is still similar to the anomalous precipitation in Fig. 2a when the $M^{\prime}$ mechanism is dominant. How-

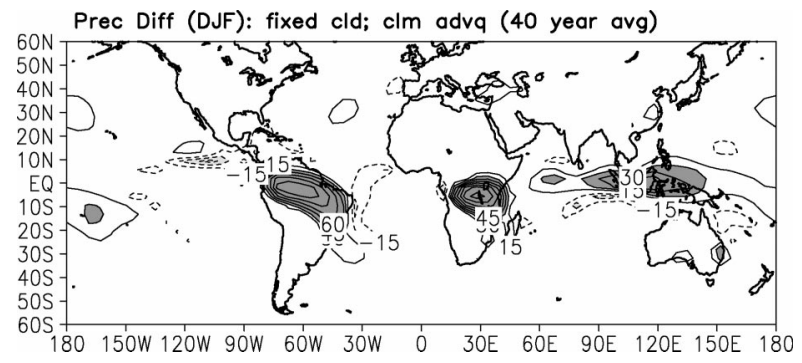

FIG. 7. DJF precipitation differences between experiments with doubled $\mathrm{CO}_{2}$ and normal $\mathrm{CO}_{2}$, in which a climatology of $\langle\mathbf{v} \cdot \nabla q\rangle$ from a control experiment is specified in both experiments. Otherwise, same as in Fig. 2a.

ever, its amplitude is only one-fifth of the precipitation anomalies of Fig. 2a. Over the margins of convective regions, the amplitude of negative precipitation anomalies also becomes smaller, and is roughly two-fifths of the negative precipitation anomalies in Fig. 2a. This reduction is due to the upped-ante mechanism rather than the effect of the $M^{\prime}$ mechanism. Convection is reduced when $M$ is fixed, weakening $-\langle\mathbf{v} \cdot \nabla q\rangle^{\prime}$, so that the amplitude of negative precipitation anomalies is smaller.

\section{d. Sensitivity}

The impacts of global warming tend to vary with model parameterizations. For instance, the specification of the cloud top for each cloud type in QTCM1 could affect the longwave cloud-radiative feedback. Here we present examples of sensitivity for the parameterized processes in QTCM1. Thus, caveats can be placed on the modeling results, and sensitivities that might be at work in other climate models can be suggested as well.

\section{1) Cloud-Radiative Climatology}

The cloud-radiative forcing strongly depends on cloud-top temperature, particularly for deep clouds. The QTCM1 version 2.3 uses a relatively low value of mean cloud top for deep clouds (336 hPa), so the longwave cloud-radiative warming effect is slightly weaker than shortwave cloud-radiative cooling in convective re-

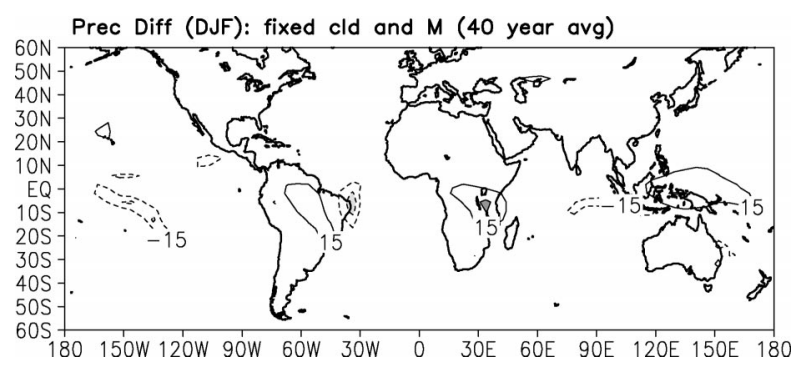

FIG. 8. As in Fig. 7 except for the differences between experiments with doubled $\mathrm{CO}_{2}$ and normal $\mathrm{CO}_{2}$, in which $M$ has been fixed within convection zones. 


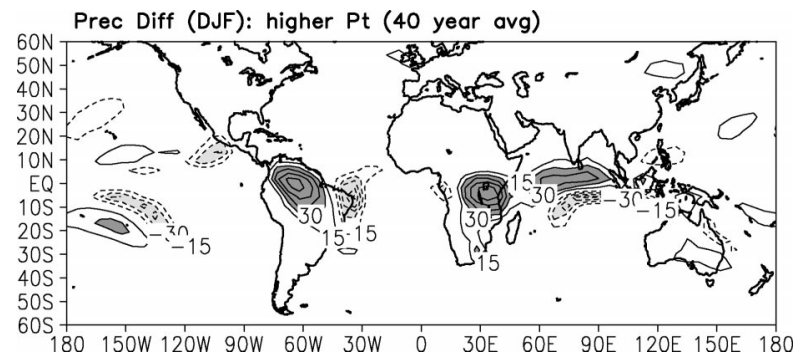

FIG. 9. As in Fig. 1 except with cloud top of high clouds at 194 $\mathrm{hPa}$. Only DJF precipitation difference is shown.

gions. Kiehl (1994) notes the near cancellation between these feedbacks. Using a model version with a new convective cloud top of $194 \mathrm{hPa}$, the cloud feedbacks nearly cancel. Figure 9 shows precipitation anomalies for a doubled $\mathrm{CO}_{2}$ experiment with this model version. Precipitation anomalies have larger magnitude than in Fig. 1a, as expected. Indeed, the anomalies are very similar to Fig. 2a, in which cloud-radiative feedbacks are suppressed, consistent with the roughly canceled longwave and shortwave effects in Fig. 9. Overall, the patterns of precipitation anomalies are similar, and the differences in cloud-radiative forcing have effects secondary to the main mechanisms that have been discussed.

\section{2) Vertical PROFile of the anOMALOUS TEMPERATURE}

In QTCM1, the vertical profile $a_{1}(p)$ of temperatures from a reference state are set by the moist adiabatic process. This is useful under conditions where convection is the dominant process determining the temperature profile or when processes are not highly sensitive to lapse rate. In global warming, lapse rate is known to play a role (Hansen et al. 1997). We assess QTCM1 sensitivity to this effect by choosing a temperature-perturbation profile, $a_{1}(p)$ such that temperature anomalies $T^{\prime}$ induced by doubled $\mathrm{CO}_{2}$ smaller than the $T^{\prime}$ obtained from the moist adiabatic process at higher altitudes. This altered $a_{1}$ profile, which is relatively constant in the vertical, is only used in the model-radiative calculation. Normal and doubled $\mathrm{CO}_{2}$ experiments are then conducted. The results are shown in Fig. 10. Since the ratio between the perturbation of OLR and $\langle T\rangle^{\prime}\left[\epsilon_{R T_{1}}^{\uparrow_{n}}\right.$ of (2.4) in $\mathrm{ZNC}$ ] is reduced, the changes in $\langle T\rangle^{\prime}$ due to the global warming effect are enhanced to balance the changes of OLR induced by doubled $\mathrm{CO}_{2}$. The larger amplitude of $\langle T\rangle^{\prime}$ increases moisture in the atmosphere which induces further warming of the surface temperature. The amplitudes of anomalous tropical precipitation in convective regions and margins are both enhanced. This enhancement of global warming impacts is consistent with the known importance of the vertical profile of $T^{\prime}$ for climate sensitivity (Hansen et al. 1997). However, the patterns of the precipitation anomalies are very similar to those obtained in the standard version. Examination (a) Prec Diff (DJF): fixed cld (40 year avg, reduced T at high z)

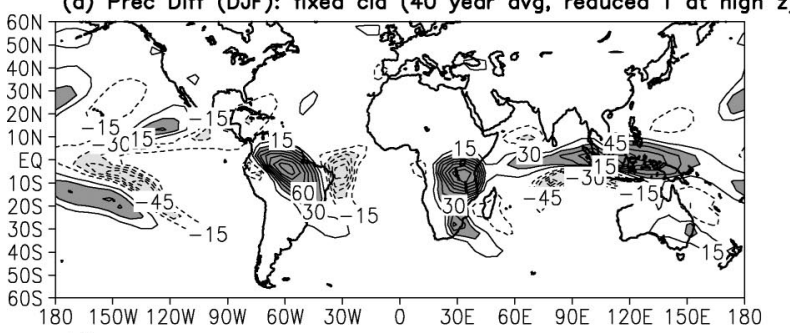

(b) Ts Diff

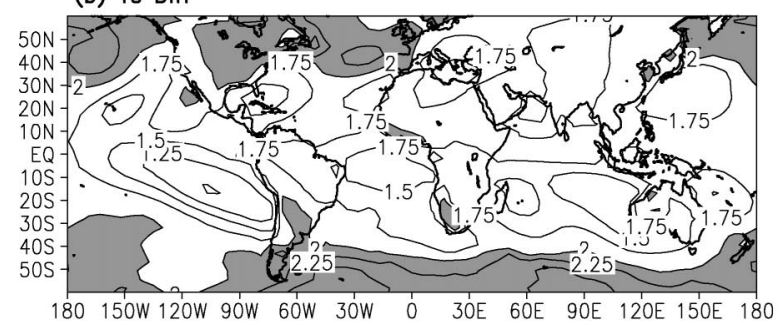

(c) That Diff

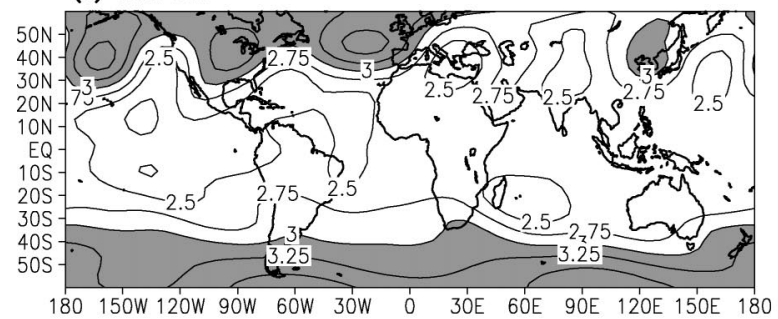

180150 W $120 \mathrm{~W}$

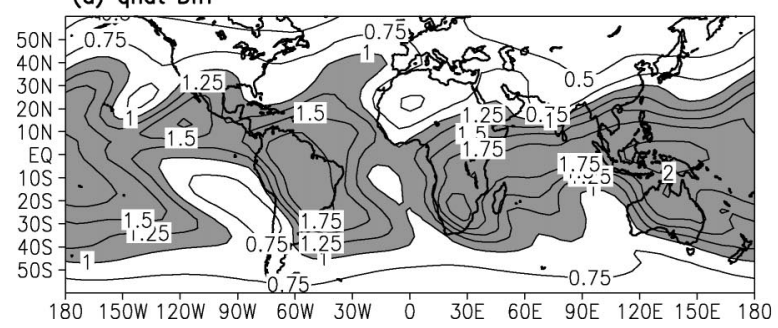

FIG. 10. As in Fig. 2 except for a different vertical profile of temperature anomalies.

of the moisture and moist static energy budgets shows that the terms responsible for the precipitation anomalies remain essentially the same as in the standard case.

\section{3) The GRoss moist StabiLity}

The gross moist stability depends on the maximum depth of convection that is prescribed in QTCM1. The higher the maximum depth of convection, the greater the value of $M$. Thus, a different choice for the maximum depth of convection for the reference state modifies the $M$ value. A pair of normal $\mathrm{CO}_{2}$-doubled $\mathrm{CO}_{2}$ experiments with a larger $M$ for the reference state (not shown) were conducted and compared to the standard experiments in Fig. 2. From the moist static energy equation, convection associated with $\boldsymbol{\nabla} \cdot \overline{\mathbf{v}}_{\mathbf{1}}$ is reduced in the control run when $M$ is larger. The associated circulation near convective regions and the horizontal 
gradient of moisture are also reduced in the control run (not shown). For precipitation anomalies induced by doubled $\mathrm{CO}_{2}$, the effect of the upped-ante mechanism is weakened, and the amplitude of the negative precipitation anomalies over the margins of convective regions is reduced. The effect of the $M^{\prime}$ mechanism is also reduced since $\boldsymbol{\nabla} \cdot \overline{\mathbf{v}}_{\mathbf{1}}$ is weakened. This implies that the strength of convection in a climate model control climatology can affect the response to greenhouse forcing. However, the effect of the modified $M$ value for the reference state is rather moderate and does not change the general results discussed in the previous sections.

\section{4) Transient EXPERIMENTS}

The results presented above are all for equilibriumdoubled $\mathrm{CO}_{2}$ runs. For transient global warming cases, a number of additional effects might occur because of ocean heat storage. In the $Q$ flux mixed layer system used here, we do not expect a full representation of the details of transient climate-change experiments because the ocean slowing of the warming can have regional feedbacks. However, we conducted simple $1 \% \mathrm{yr}^{-1} \mathrm{CO}_{2}$ increase experiments (not shown). By the time of $\mathrm{CO}_{2}$ doubling, the upped-ante and $M^{\prime}$ mechanisms have the leading role found in the equilibrium experiments above.

\section{Discussion and conclusions}

In the context of an intermediate complexity atmospheric model/mixed layer ocean for doubled $\mathrm{CO}_{2}$ runs, a relatively straightforward set of mechanisms has been found for regional tropical precipitation anomalies under global warming. The increased greenhouse gas warms the atmosphere by absorbing longwave radiation and reducing OLR. This warming is relatively uniform in space and affects convection since a warmer free troposphere affects the buoyancy of parcels unless the $\mathrm{ABL}$ is modified as well. Under the quasi-equilibrium convective closure, ABL moisture tends to increase to reestablish parcel buoyancy, compensating for the increased tropospheric temperature. Roughly speaking, moisture increases to maintain positive CAPE in convection zones. This CAPE-mediated effect moistens the atmosphere over convective regions but has no impact over nonconvective regions, so a spatial gradient in the change of moisture is induced. In nonconvective regions, different balances determine moisture, which does not increase as much as in convective regions. This process that creates the spatial pattern of moisture anomalies is the first step in inducing the anomalous precipitation. Some expected mechanisms for creating the gradient of the moisture anomalies turn out to be insignificant, such as evaporation. A side effect of the moisture anomaly pattern is that an increased greenhouse effect associated with the moisture anomalies warms surface temperature more in convective regions than in nonconvective regions.

Two main mechanisms associated with the moisture anomalies then produce the anomalous tropical precipitation. The "upped-ante mechanism" is responsible for the negative precipitation anomalies over the margins of convective regions and the "anomalous gross moist stability $\left(M^{\prime}\right)$ mechanism" is responsible for the positive precipitation anomalies over convective regions. The upped-ante mechanism, initially presented in NCS03, is associated with the anomalies of the horizontal advection of moisture. In regions where there is inward flow from a nonconvective region into a convection zone, the gradient of moisture anomalies discussed above implies import of dry air into the margin of the convection zone, reducing precipitation. The increased tropospheric temperature "ups the ante" for the amount of ABL moisture that must be present for convective events to occur. In the center of convective regions, there is a plentiful moisture supply, so the increased "convective ante" is easily met. However, in the margins of convective regions, increases in ABL moisture are opposed by the inflow of dry air, so the increased ante implies a drop in precipitation. This is why negative precipitation anomalies occur even though moisture anomalies are everywhere positive; the moisture increase must be considered relative to the increased ante set by the warming. The drying effect of the anomalous moisture transport also induces a subsidence feedback that greatly enhances the reduction of precipitation in these margins of convective regions. The $M^{\prime}$ mechanism is induced by the change of the gross moist stability. In QTCM1, the increase of moisture reduces the gross moist stability $(M)$, so the $M^{\prime}$ mechanism has a positive feedback on convection. The $M^{\prime}$ mechanism enhances the convergence over convective regions, so that convection becomes even stronger and precipitation increases over convective regions.

Besides these two main mechanisms, there are some secondary mechanisms that also contribute to the anomalous precipitation. The first is the direct moisture effect that is associated with the variation of $M_{q}$. When $M_{q}$ is enhanced by the positive moisture anomalies that are induced by the CAPE-mediated effect, the direct moisture effect increases the precipitation over convective regions. The direct moisture effect is responsible for about $30 \%$ of the amplitude of the positive anomalous precipitation over convective regions. The second mechanism is the cloud-radiative effect. The net cloud-radiative feedback is relatively weak in QTCM1 due to the cancellation between infrared and shortwave effects, and its sign depends on the cloud top of high clouds. The third mechanism is the evaporation effect, which is also weak, based on the moisture budget analysis, and is not the dominant effect for creating the gradient of the moisture anomalies.

The results here address mechanisms that apply for an equilibrated warming. Additional effects may occur 
that are associated with the time dependence of warming, for instance, if ocean heat capacity slows surface warming relative to that of the troposphere (Barnett et al. 2001; Levitus et al. 2001). Effects associated with ocean dynamics are also expected to react to and feed back on the changes induced by the mechanisms discussed here. There has been considerable effort to validate patterns of climate change against observations over the past few decades (Boer et al. 2000b; Gillett et al. 2003; Houghton et al. 2001; Levitus et al. 2001; Mann et al. 1998; Stott et al. 2000; Tett et al. 1999; Wigley et al. 1998). One might ask at what point in the global warming process one might expect to observe the regional patterns implied by these mechanisms. First, we note that the results here do not include anthropogenic aerosol effects, which can have substantial radiative impacts and the potential to affect typical regional precipitation (Ramanathan et al. 2001; Rotstayn and Lohmann 2002). Such aerosol effects may be important to twentieth-century trends and to the near future, although because of long residence times, greenhouse gas forcing typically dominates projections for the mid- and late twenty-first century (Houghton et al. 2001). Extending analysis of moist dynamical pathways to include aerosol effects would clearly be desirable. Second, the large internal climate variability of regional precipitation suggests that statistically significant validation of climate models for these patterns may be some decades in the future (Boer et al. 2000b). However, the role of these mechanisms in El Niño teleconnections is being examined in parallel work (NCSO3; H. Su and J. D. Neelin 2003, unpublished manuscript). It appears that the upped-ante mechanism is also responsible for drought regions over South America and the Atlantic ITCZ in the remote response to El Niño. To the extent that the regional tropical precipitation anomalies induced by global warming and interannual variations are governed by similar mechanisms, the interannual variability can be used for model validation.

Sensitivity related to climate-model parameterizations implies caveats for the simulation of regional tropical-climate change. Among sensitivity tests examined here, the longwave cloud-radiative forcing associated with the climatology of the high cloud top modifies the amplitude of the positive radiative feedback on convection, but only moderately. The vertical profile of the anomalous temperature induced by doubled $\mathrm{CO}_{2}$ is important in determining the amplitude of the warming tendency. A crucial factor in regional precipitation change is the variation in anomalous gross moist stability that underlies the $M^{\prime}$ mechanism. Unfortunately, there is no definite theory for the variation of $M^{\prime}$. In Yu et al. (1998), $M$ is roughly estimated from observations and its variations involve two large effects that have significant cancellation between them: the lowlevel moisture effect and the maximum depth of convection effect. It seems likely that $M^{\prime}$ variations in GCMs will be sensitive to the particular cumulus pa- rameterization used. We conjecture that differences in $M^{\prime}$ variation among climate models may be a significant factor in differences in the projection of regional tropical precipitation change. The development of $M^{\prime}$ theory is necessary for further understanding of the $M^{\prime}$ mechanism.

Acknowledgments. This work was supported under the National Science Council Grant 91-2111-M-001002, National Science Foundation Grant ATM-0082529, and National Oceanic and Atmospheric Administration Grant NA16GP2004. The authors thank J. E. Meyerson for graphics.

\section{REFERENCES}

Allen, M. R., and W. J. Ingram, 2002: Constraints on future changes in climate and the hydrologic cycle. Nature, 419, 224-232.

Barnett, T. P., D. W. Pierce, and R. Schnur, 2001: Detection of anthropogenic climate change in the world's oceans. Science, 292, 270-274.

Betts, A. K., and M. J. Miller, 1993: The Betts-Miller scheme. The Representation of Cumulus Convection in Numerical Models of the Atmosphere, Meteor. Monogr., No. 46, Amer. Meteor. Soc., 107-121.

Boer, G. J., G. Flato, and D. Ramsden, 2000a: A transient climate change simulation with greenhouse gas and aerosol forcing: Projected climate to the twenty-first century. Climate Dyn., 16, $427-$ 450 .

_ —_, M. C. Reader, and D. Ramsden, 2000b: A transient climate change simulation with greenhouse gas and aerosol forcing: Experimental design and comparison with the instrumental record for the twentieth century. Climate Dyn., 16, 405-425.

Cess, R. D., and Coauthors, 1996: Cloud feedback in atmospheric general circulation models: An update. J. Geophys. Res., 101, $12791-12794$.

Chiang, J. C. H., and A. H. Sobel, 2002: Tropical tropospheric temperature variations caused by ENSO and their influence on the remote tropical climate. J. Climate, 15, 2616-2631.

Chou, C., and J. D. Neelin, 1996: Linearization of a longwave radiation scheme for intermediate tropical atmospheric models. $J$. Geophys. Res., 101, 15 129-15 145.

— Geophys. Res. Lett., 26, 1295-1298.

—_ - - and H. Su, 2001: Ocean-atmosphere-land feedbacks in an idealized monsoon. Quart. J. Roy. Meteor. Soc., 127, 18691891.

Dai, A., G. A. Meehl, W. M. Washington, T. M. L. Wigley, and J. M. Arblaster, 2001a: Ensemble simulation of twenty-first century climate changes: Business-as-usual versus $\mathrm{CO}_{2}$ stabilization. Bull. Amer. Meteor. Soc., 82, 2377-2388.

—_, T. M. L. Wigley, B. A. Boville, J. T. Kiehl, and L. E. Buja, 2001b: Climates of the twentieth and twenty-first centuries simulated by the NCAR climate system model. J. Climate, 14, 485519.

Delworth, T. L., and T. R. Knutson, 2000: Simulation of early 20th century global warming. Science, 287, 2246-2250.

Douville, H., F. Chauvin, S. Planton, J.-F. Royer, D. Salas-Mélia, and S. Tyteca, 2002: Sensitivity of the hydrological cycle to increasing amounts of greenhouse gases and aerosol. Climate Dyn., 20, 45-68.

Fu, Q., and K. N. Liou, 1993: Parameterization of the radiative properties of cirrus clouds. J. Atmos. Sci., 50, 2008-2025.

Gillett, N. P., F. W. Zwiers, A. J. Weaver, and P. A. Stott, 2003: Detection of human influence on sea-level pressure. Nature, 422 , 292-294. 
Hansen, J., M. Sato, and R. Ruedy, 1997: Radiative forcing and climate response. J. Geophys. Res., 102, 6831-6864.

Harshvardhan, R. Davies, D. A. Randall, and T. G. Corsetti, 1987: A fast radiation parameterization for general circulation models. J. Geophys. Res., 92, 1009-1016.

Held, I. M., and B. J. Soden, 2000: Water vapor feedback and global warming. Annu. Rev. Energy Environ., 25, 441-475.

Houghton, J. T., Y. Ding, D. J. Griggs, M. Noguer, P. J. van der Linden, X. Dai, K. Maskell, and C. A. Johnson, Eds., 2001: Climate Change 2001: The Scientific Basis. Cambridge University Press, 881 pp.

Jin, F.-F., Z.-Z. Hu, M. Latif, L. Bengtsson, and E. Roeckner, 2001: Dynamical and cloud-radiation feedbacks in El Niño and greenhouse warming. Geophys. Res. Lett., 28, 1539-1542.

Kiehl, J. T., 1994: On the observed near cancellation between longwave and shortwave cloud forcing in tropical regions. J. Climate, 7, 559-565.

Levitus, S., J. I. Antonov, J. Wang, T. L. Delworth, K. W. Dixon, and A. J. Broccoli, 2001: Anthropogenic warming of earth's climate system. Science, 292, 267-270.

Lucarini, V., and G. L. Russell, 2002: Comparison of mean climate trends in the Northern Hemisphere between National Centers for Environmental Prediction and two atmosphere-ocean model forced runs. J. Geophys. Res., 107, 4269, doi:10.1029/ 2001JD001247.

Mann, M. E., R. S. Bradley, and M. K. Hughes, 1998: Global-scale temperature patterns and climate forcing over the past six centuries. Nature, 392, 779-787.

Meehl, G. A., W. D. Collins, B. A. Boville, J. T. Kiehl, T. M. L. Wigley, and J. M. Arblaster, 2000: Response of the NCAR climate system model to increased $\mathrm{CO}_{2}$ and the role of physical processes. J. Climate, 13, 1879-1898.

Mitchell, J. F. B., W. J. Ingram, and J. A. Lowe, 2000: The effect of stabilizing atmospheric carbon dioxide concentration on global and regional climate change. Geophys. Res. Lett., 27, 2977-2980.

Neelin, J. D., and I. M. Held, 1987: Modeling tropical convergence based on the moist static energy budget. Mon. Wea. Rev., 115, 3-12.

— vective adjustment and the Madden-Julian oscillation. Part I: Analytical theory. J. Atmos. Sci., 51, 1876-1894.

—, and N. Zeng, 2000: A quasi-equilibrium tropical circulation model-Formulation. J. Atmos. Sci., 57, 1741-1766.

- C. Chou, and H. Su, 2003: Tropical drought regions in global warming and El Niño teleconnections. Geophys. Res. Lett., 30, 2275, doi:10.1029/2003GL018625.

Ramanathan, V., P. J. Crutzen, J. T. Kiehl, and D. Rosenfeld, 2001: Aerosols, climate, and the hydrological cycle. Science, 294, 2119-2124.

Roeckner, E., L. Bengtsson, J. Feichter, J. Lelieveld, and H. Rodhe, 1999: Transient climate change simulation with a coupled at- mosphere-ocean GCM including the tropospheric sulfur cycle. J. Climate, 12, 3004-3032.

Rotstayn, L. D., and U. Lohmann, 2002: Tropical rainfall trends and the indirect aerosol effect. J. Climate, 15, 2103-2116.

Santer, B. D., and Coauthors, 2000: Interpreting differential temperature trends at the surface and in the lower troposphere. Science, 287, 1227-1232.

Semenov, V., and L. Bengtsson, 2002: Secular trends in daily precipitation characteristics: Greenhouse gas simulation with a coupled AOGCM. Climate Dyn., 19, 123-140.

Stevens, B., J. Duan, J. C. McWilliams, M. Münnich, and J. D. Neelin, 2002: Entrainment, Rayleigh friction, and boundary layer winds over the tropical Pacific. J. Climate, 15, 30-44.

Stott, P. A., S. F. B. Tett, G. S. Jones, M. R. Allen, J. F. B. Mitchell, and G. J. Jenkins, 2000: External control of 20th-century temperature by natural and anthropogenic forcings. Science, 290, $2133-2137$.

Su, H., and J. D. Neelin, 2002: Teleconnection mechanisms for tropical Pacific descent anomalies during El Niño. J. Atmos. Sci., 59, 2694-2712.

Tett, S. F. B., J. F. B. Mitchell, D. E. Parker, and M. R. Allen, 1996 Human influence on the atmospheric vertical temperature structure: Detection and observations. Science, 274, 1170-1173.

— , P. A. Stott, M. R. Allen, W. J. Ingram, and J. F. B. Mitchell, 1999: Causes of twentieth-century temperature change near the earth's surface. Nature, 399, 569-572.

Washington, W. M., and Coauthors, 2000: Parallel climate model (PCM) control and transient simulations. Climate Dyn., 16, 755774.

Watterson, I. G., and M. R. Dix, 1999: A comparison of present and doubled $\mathrm{CO}_{2}$ climates and feedbacks simulated by three general circulation models. J. Geophys. Res., 104, 1943-1956.

—_ S. P. O'Farrell, and M. R. Dix, 1997: Energy and water transport in climates simulated by a general circulation model that includes dynamic sea ice. J. Geophys. Res., 102, $11027-11037$.

Wigley, T. M. L., R. L. Smith, and B. D. Santer, 1998: Anthropogenic influence on the autocorrelation structure of hemispheric-mean temperatures. Science, 282, 1676-1679.

Williams, K. D., C. A. Senior, and J. F. B. Mitchell, 2001: Transient climate change in the Hadley Centre models: The role of physical processes. J. Climate, 14, 2659-2674.

Yonetani, T., and H. B. Gordon, 2001: Simulated changes in the frequency of extremes and regional features of seasonal/annual temperature and precipitation when atmospheric $\mathrm{CO}_{2}$ is doubled. J. Climate, 14, 1765-1779.

Yu, J.-Y., and J. D. Neelin, 1994: Modes of tropical variability under convective adjustment and the Madden-Julian oscillation. Part II: Numerical results. J. Atmos. Sci., 51, 1895-1914.

— C. Chou, and J. D. Neelin, 1998: Estimating the gross moist stability of the tropical atmosphere. J. Atmos. Sci., 55, 13541372.

Zeng, N., J. D. Neelin, and C. Chou, 2000: A quasi-equilibrium tropical circulation model-Implementation and simulation. $J$. Atmos. Sci., 57, 1767-1796. 